\title{
Variations in Strategic Philosophy among American and Mexican Managers
}

John A. Parnell

\section{Introduction}

Although numerous studies investigating business strategy have been published, most have examined organizations in the developed world, most notably the United States (Henderson and Mitchell, 1997; Kotha et al., 1995). Many elements of the present consensus developed from studies of Western firms may be directly applicable to emerging nations (Lowe et al., 2000). Unfortunately, however, many of these studies have not provided complete answers to many of the core strategic dilemmas faced by top executives (Hambrick and Fredrickson, 2001).

There is increasing evidence that strategy formulation is linked to the top executive's personal philosophy and personality (Kotey and Meredith, 1997). Management’s self-interest, their personalities, interpretations, and influences on strategy have also been examined (Guth and MacMillan, 1986; Janis, 1972; Smircich and Stubbart, 1985; Walsh and Fahey, 1986).

In many respects, strategic management remains an intuitive and philosophical undertaking. As such, strategic managers are still faced with five critical judgment calls when formulating strategy for their companies, each of which involves apparent contradictions that must be negotiated if a firm is to succeed. This paper examines the perspectives of American and Mexican managers along these five critical areas. Conclusions and directions for future research are also discussed.

\section{Question 1: Is strategy an art or a science?}

The art versus science debate is a key issue in strategy formulation. While it may appear to be an academic dispute at first glance, one's perception of the strategy phenomena - and more specifically the process of strategy formulation - is a key building block of strategy.

The difference between the art and science interpretations of strategy is substantial and noteworthy. According to the art perspective, the lack of environmental predictability and the fast pace of change render elaborate strategy planning as suspect at best. Instead, strategists should incorporate large doses of creativity and intuition in order to design a comprehensive strategy for the firm (Ford and Gioia, 2000). In contrast, followers of the science perspective see the business environment as largely objective, analyzable, and at least somewhat predictable. As such, strategic managers should follow a systematic process of environmental, competitive, and internal analysis, and build the organization's strategy on this foundation (see Table I).

Most of the strategy literature has traditionally favored the science, or planning model, whereby strategic managers are encouraged to systematically assess the firm's external environment and evaluate the pros and cons of myriad alternatives before formulating strategy. The search for causal relationships and objectivity are central to the process. By definition, strategic managers should be trained, highly skilled analytical thinkers capable of digesting a myriad of objective data and translating it into a desired direction for the firm.

In contrast, Mintzberg's (1987) notion of a craftsman-encompassing individual skill, dedication, and perfection through mastery of detail embodies the artistic model. The strategy artist senses the state of the organization, interprets its subtleties, and seeks to mold its strategy like a potter molds clay. The artist visualizes the outcomes associated with various alternatives and ultimately charts a course 
TABLE I

The art and science approaches to strategy

\begin{tabular}{lcc}
\hline \multicolumn{1}{c}{ Characteristic } & Art & Science \\
\hline Systematic analysis of environment & Difficult at best & Possible and essential \\
Environmental predictability & Very limited & Extensive \\
Perception of environment & Subjective & Objective \\
Planning steps & Varies by organization; & organizations \\
& no one best way & Analysis \\
Key intellectual influence & Imagination & \\
& & \\
\hline
\end{tabular}

based on holistic thinking, intuition, and imagination.

Mintzberg (1987) coined the terms “deliberate” and "emergent” strategies in part to distinguish between the strategies that emanate from the two schools of thought. Nonetheless, most scholars continued to proceed with the assumption that deliberate strategies are preferred, and emergent strategies invariably result from ineffective planning and/or environmental unpredictability.

The relevance of this philosophical debate is clear. "Strategy scientists" tend to minimize or reject altogether the role of imagination and creativity in the strategy process, and are not generally receptive to alternatives that emerge from any process other than a comprehensive, analytical approach. "Strategy artists" often view strategic planning exercises as time poorly spent and may not be as likely as those in the science school to make the effort necessary to maximize the value of a formal planning process (Hamel, 1996; Huffman, 2001).

The prevailing wisdom is that strategy is both an art and a science. On the one hand, following a comprehensive process of strategy development and implementation is likely to improve prospects for success. This may be more critical for businesses that face low levels of uncertainty (Courtney et al., 1997). On the other hand, however, the creative dimensions of strategy, such as brainstorming and qualitative forecasting, should not be eschewed

American and Mexican managers are similar in that both groups tend to emphasize compartmentalization, rationality, and objectivity in strategic decision-making. Given the recent trends in the United States toward creativity in strategy making, however, American managers may be more inclined to adopt an artistic perspective on strategy (Scarborough, 1998; Wall, 1990).

\section{PROPOSITION 1. American managers will view strategy formulation more as an art than will their Mexican counterparts.}

\section{Question 2: Should strategies be visible or hidden?}

In many respects, the evidence of an organization's strategy can be seen in its employees. Its customers also appreciate knowing what a company is attempting to accomplish and prospective investors tend to hesitate when they do not have a clear vision of the firm's position and future priorities. Sharing strategic information with lower level managers and employees may enhance both 
job comprehension and organizational commitment. Hence, the arguments for a "public" strategy are intuitively obvious.

However, a number of challenges emanate from a free dissemination of the organization's strategy. Open discussion to any group outside of top management (e.g., middle managers, investors, community leaders, etc.) may be translated into competitive intelligence for rival firms. Participants in the strategy process become more attractive to other industry players and may be lured away for competitive reasons. As a result, most strategic managers argue for at least some degree of strategy privacy.

The Chinese warrior Sun Tzu is often cited as an historical proponent of the hidden strategy perspective (Michaelson, 2001). In the military context, he argued that all war is based on deception, and that effective military maneuvers are ones that are not easily predicted by one's opponent. Business strategists, therefore, surmise that the best strategy must be one that competitors cannot understand. Sharing strategic information with stakeholders ultimately aids competitors in the comprehension process.

It is difficult to argue with this notion of deceptive strategies prima facie. However, strategic secrecy may not only keep a strategy hidden from those who might wish to exploit it, but also from those who can contribute to its development or are responsible for implementing it. However, in an environment where managers frequently move from one company to another, forthright strategic discussions with employees may ultimately result in sharing confidential strategic intentions with competitors. In addition, effective communication with investors and business media can be critical to the maintenance of a firm's stock price, although it can involve the dissemination of sensitive information.

In a perfect world, strategic managers would involve all key individuals in the organization, as well as other key stakeholders (e.g., suppliers, customers, etc.) in the strategic management process, without disseminating key knowledge to those who may have a current or potential competitive interest against the firm. Although this balancing act is difficult, if not impossible to accomplish, distinguishing the most critical and confidential data and decisions from that which is of little value or cannot be readily concealed is central to the process. Specifically, many analysts believe that executives should identify a narrow scope of data and competitive intelligence that should remain confidential to top managers, and then take steps to ensure that such information is not disseminated beyond the inner circle.

This debate is an interesting one in the American and Mexican contexts. Formality and trust are central to success in the Mexican business environment. Unlike their American counterparts, diplomacy and the avoidance of criticism is essential to daily business activities in Mexico (Stephens and Greer, 1995). On the positive side, Mexican managers often operate effectively as a team. On the negative side, however, Mexican managers tend to avoid bad news and are prone to escalation of commitment to losing courses of action.

Within Mexican organizations, business is conducted only with people one likes personally (Gutierrez, 1993). In contrast, American companies emphasize formal contracts and tend to conduct business wherever it is profitable (Rusted et al., 1993). A number of explanations - including the lack of a predictable and reliable legal system in Mexico, and the strength of Mexican family ties - have been proposed as explanations of this phenomenon. 
Nonetheless, this emphasis on formality and trust may translate into a greater emphasis on maintaining secrecy in strategy content.

PROPOSITION 2. Mexican managers will more greatly emphasize the need for strategy content to remain hidden than will their American counterparts.

\section{Question 3: Is strategic commitment more important than strategic flexibility?}

An organization's strategic managers may choose to commit to a strategic course of action for an extended period of time and enjoy the benefits of organizational teaming and a clear customer image. Alternatively, an organization can remain flexible so that it does not become committed to products, technology, or market approaches that may become outdated. In a perfect world, organizations commit to predictable, successful courses of action, and strategic change is only incremental. In the real world, however, outcomes are not always predictable and the environment is dynamic. Hence, for most firms, strong arguments can usually be made for substantial strategic shifts, even when performance is not lacking (Grewel and Tansuhaj, 2001).

Interestingly, the popular business press has been consistently inconsistent with regard to this debate over the years. When traditional firms perform poorly, their strategic managers are exhorted to promote flexibility and strategic renewal to improve profitability. In contrast, when bold strategic changes fail, pundits assert that a company must return to its "core business." Hence, it is easy to migrate freely from one side of the debate to the other, often with convincing empirical and intuitively appealing arguments.

Proponents of the strategic change and flexibility school make four primary arguments. First, strategies tend to yield superior performance when implemented in appropriate environments. Without strategic flexibility, an organization cannot adapt to its changing external environment (Parnell, 1997). Even if an organization's strategy is effectively aligned with its environment, an environmental shift may necessitate strategic change to maintain alignment (Hannan and Freeman, 1977; Ulrich, 1987; Whipp et al., 1989; Wemerfelt and Kamani, 1987).

Second, an organization can seek first mover advantages by entering a new market or develop a new product or service prior to the competition (Gannon et al., 1992; Petersen and Welch, 2000). Being a first mover can help secure access to scarce resources, increase the organization's knowledge base, and result in substantial long term competitive advantage, especially when switching costs are high (Lieberman and Montgomery, 1988; Mascarenhas, 1992).

Third, an organization must modify its strategy as its set of unique human, physical, capital, and informational resources change (Barney, 1991; Lado et al., 1992). Proponents of the resource based view of strategy have noted that competitive advantage often occurs from such organizational attributes as informational asymmetries (Barney, 1986), culture (Fiol, 1991), resource accumulation (Dierickx and Cool, 1989), and the minimization of transaction costs (Camerer and Vepsalainen, 1988), and that strategies should reflect change in these capabilities. Resource shifts necessitating strategic change may be more prevalent in some organizations than in others (Hitt et al., 1998).

In a similar vein, strategic change can improve an organization's ability to adapt by forcing healthy changes within the business. The initial pain associated with change may be offset by the emergence 
of a lean, rejuvenated organization with a fresh focus on its goals and objectives. On the contrary, organizations that maintain strategic consistency over time may become stagnant, limiting the creativity and potential contributions of its members.

Fourth, strategic changes may be necessary if desired performance levels are not being attained by the organization. In many cases, top managers may believe that a change in strategy will improve the ability of the business to generate revenues or profits, increase market share, and/or improve return on assets or investment. Many studies have concluded that declining profitability is the most common catalyst for strategic change (Backer, 1989; Webb and Dawson, 1991). Interestingly, organizational performance, age, and length of tenure of the founding entrepreneur influence the degree to which a founding strategy endures and thus, the prospects for strategic change (Boeker, 1989). In fact, new CEOs are often recruited to attempt strategic changes upon entering the organization (Greiner and Bhambri, 1989).

Proponents of the strategic consistency school argue for strategy stability on four grounds. First, a change in any key strategic, environmental, or organizational factor may entice strategic managers in a business to modify its strategy to incorporate these changes. However, since such variables are constantly evolving, this is challenging process, and inaction may minimize uncertainty. Indeed, a strategic change is most risky when competitors are better equipped to respond if it is successful (Wemerfelt and Kamani, 1987). Further, a successful strategic change is often seen as unsuccessful in the short run, and therefore must endure efforts to return to the former strategy when organizational "losers" - typically those whose careers may suffer as a result of the change-will mount a stiff opposition (Gaertner, 1989; Yoshihara, 1990). Further, strategic change can challenge the assumptions of all organizational members and may be difficult to implement even with employee support (Saffold, 1988; Scholes, 1991).

Second, it is likely that measures required to implement a change in strategy may necessitate substantial outlays of capital. For example, a shift from a prospector or analyzer strategy to a defender strategy may require investments in sophisticated production equipment to lower production costs, a characteristic more important to effective implementation of a defender strategy (Miles and Snow, 1978). Likewise, a shift from a defender or analyzer strategy to a prospector strategy may require outlays to develop or enhance research and development facilities.

Third, consumer confusion may result from strategic change. For example, if a business employing a low cost strategy attempts to switch to a differentiation strategy, its price-oriented customers may become confused and leave in pursuit of another low cost leader, while those willing to pay a premium price for differentiated products may not recognize the organization's strategic change. Many will likely recall remnants of the previous strategy - perhaps advertising campaigns - and may not even consider a transaction with the organization.

Finally, even when strategic change results in a successful new product or service, there is no assurance that this success can be maintained. Indeed, competitors may distort consumer perceptions and reap the benefits of the initial strategic change. For example, a number of consumer goods companies are "imitators" (Foxman et al., 1990), and many consumers purchase the imitation product thinking it is the original. If the consumer dislikes the product, this dissatisfaction can be transferred to the original. If the consumer likes the product, the consumer may realize that the product is an imitator and transfer the positive associations with the original product to that of the imitator. Either scenario can prove costly to the originator (Loken et al., 1986). 
Unlike their American counterparts, Mexican managers are trained for survival in turbulent environments (Kras, 1995). This stark difference in the American and Mexican planning environments may place a premium on flexibility as part of any effective strategy. In the U.S., sacrificing agility for efficiency may be a viable tradeoff in many industries. The predictability of the American business environment coupled with sophisticated forecasting techniques may serve as the structural foundation for the defender approach. As such, Mexican managers would be expected to emphasize flexibility in strategy content more than American managers.

PROPOSITION 3. Strategic flexibility will be emphasized more by Mexican managers than by their American counterparts.

\section{Question 4: What degree of risk is inherent in strategy formulation? How much competitive intelligence is enough?}

Strategy is about making choices (Porter, 1985), some of which appear to be riskier than others. Environmental scanning is at best an inexact science, and strategic managers are inevitably left with varying amounts of risk and uncertainty associated with each strategic alternative they possess. According to one school of thought, strategy formulation is inherently risky, and top managers should not forego attractive opportunities because of a lack of certainty. However, a second school contends that risk reduction is the primary responsibility of top management. Executives, therefore, should be skilled at processing information so that risk can be avoided - or at least severely minimized - in strategy formulation.

The current trend toward the acknowledgement of risk notwithstanding, fast-food giant McDonald's historically has eschewed risk in strategy making, opting instead to promote and expand its concept of consistent, quality hamburgers and related food products. Although McDonald's is generally considered to be a successful firm, it is interesting to note, however, that of its three most substantial innovations over the past three decades - the Big Mac, the Egg McMuffin, and Chicken McNuggets - two were invented by franchisees and the third was launched by the company only after seven years of testing (Ghemawat and Khanna, 2000).

The literature concerning risk and strategy formulation among Mexican executives is not well developed. As such, it is proposed that no significant differences in risk tendency will exist between the two groups.

PROPOSITION 4. There will be no significant differences in risk perceptions between American and Mexican managers.

\section{Question 5: Should top-down or bottom-up approaches to strategy formulation be utilized?}

Most scholars agree that at least some nonexecutive level managers should be involved in the strategy formulation process. The key issue, however, is the most appropriate degree of involvement. Top-down proponents argue that seasoned executives are the only ones in the organization with the collective experience, acumen, and fiduciary responsibility required to chart the strategy. In contrast, bottom-up proponents argue that a strategy eventually must be implemented by middle- and lowerlevel managers, whom therefore should play a central role in its development. 
Indeed, research has more greatly emphasized the role of multiple managers in building the superior performing organization (Hurst et al., 1990; Markoczy, 2001; Sayles, 1993; Wooldridge 1990; Wright et al., 1990). However, much of the strategy research in the 1970s and early 1980s followed Ansoff (1965) and others (Andrews, 1971; Schendel and Hofer, 1979), relying on perceptions of the top manager for insight into an organization's strategic intentions. Although the concept of middle management involvement in strategy is not a recent phenomenon, the last decade has produced evidence to suggest that strategy formulation and implementation can reflect a diverse array of top and middle management inputs (Hart, 1992; Hiam, 1993; Westphal and Fredrickson, 2001). Mintzberg and Waters' (1985) notion of deliberate and emergent strategies acknowledges the significant role of top and middle managers in the strategic management process. As Nichol (1992, p. 27) observed, strategy synchronization is a team effort, requiring contributions and knowledge from both middle and senior managers.

Leadership styles in the United States tend to be participative whereas autocratic and paternalistic styles are more common in Mexico (Morales, 1997). Anecdotal evidence suggests that participative styles are becoming more popular in Mexico, but change has been slow has is not widely seen in the strategy formulation process (Bailey, 1993; Kras, 1995; Nichols et al., 1999). This difference may be linked to competing perspectives on loyalty, as loyalty to one's immediate superior and organization is more widely valued among Mexican firms (Gutierrez, 1993).

\section{PROPOSITION 5. Mexican managers will emphasize top management control of the strategy formulation process more than their American counterparts will.}

\section{Methods}

Between six and ten items were developed as potential measures for each of the five factors. An initial survey of all of the items was administered to 177 managers in the southeastern United States. Following the initial data analysis, a number of items were eliminated based on wording, loading, or redundancy concerns. In the interest of parsimony, three items were selected as measures for each factor. The resulting survey instrument contained these fifteen items, as well as a previously validated three-item scale to measure satisfaction with organizational performance (Parnell, 2000; Parnell and Carraher, 2002).

To test the propositions, the final instrument was administered to 402 middle and upper level managers from Texas and Mexico. 57\% (229) of whom reported American citizenship, 43\% (173) Mexican citizenship. 68\% of the respondents were male, 32\% female. The Mexican managers were fluent in English and well-versed in American business practices.

Respondents represented a variety of industries. Although this phenomenon introduces some degree of cross-industry variation into the study, the constructs and relationships were hypothesized to be consistent across industries. Although support for relationships with a cross industry sample can be more difficult to engender, doing so can lend greater credence to the generalizability of the findings.

The principal components (Harman and Jones, 1966) factor extraction technique resulted in single factor loadings in the five scales ranging from 0.535 to 0.842 (see Table II). Scholars and statisticians have suggested desired minimum loadings ranging from 0.500 to 0.700 . Coefficient alpha (Cronbach, 1951) for the scales ranged from 0.513 to 0.652, indicating that the scales have a moderate level of internal consistency, an important indication of reliability (Kuratko et al., 1990; Peter, 1979). 
TABLE II

Results of factor analyses

\begin{tabular}{|c|c|c|}
\hline Item & Summary & Loading \\
\hline \multicolumn{3}{|c|}{ ART subscale (alpha $=0.5814)$} \\
\hline ART1 & Strategies should be meticulously planned & 0.636 \\
\hline ART2 & Strategy formulation is an art & 0.764 \\
\hline ART3 & Strategy formulation should be approached as a scientific process & 0.805 \\
\hline \multicolumn{3}{|c|}{ HIDE subscale (alpha $=0.5214)$} \\
\hline HIDE1 & Keep the details of strategies secret & 0.651 \\
\hline HIDE2 & Communicate openly the details of strategies to employees & 0.660 \\
\hline HIDE3 & Communicate the details of strategies to the media & 0.737 \\
\hline \multicolumn{3}{|c|}{ FLEX subscale (alpha $=0.6518)$} \\
\hline FLEX1 & Strategies should remain flexible so that they can easily change & 0.761 \\
\hline FLEX2 & Stick to the strategy over the long term & 0.719 \\
\hline FLEX3 & Maintain consistency in strategies over time & 0.842 \\
\hline \multicolumn{3}{|c|}{ RISK subscale $($ alpha $=0.5479)$} \\
\hline RISK1 & Risk cannot and should not be avoided when formulating strategies & 0.699 \\
\hline RISK2 & Responsibility of the executive to reduce risks inherent in strategy & 0.535 \\
\hline RISK3 & A certain amount of risk is inevitable & 0.780 \\
\hline \multicolumn{3}{|c|}{ TOP subscale $($ alpha $=0.5128)$} \\
\hline TOP1 & Strategies should be handed down from the top & 0.728 \\
\hline TOP2 & Maximum input from all employees in the organization & 0.663 \\
\hline TOP3 & Executives should develop strategies for the company & 0.742 \\
\hline \multicolumn{3}{|c|}{ PERSAT subscale (alpha $=0.7747)$} \\
\hline PERSAT1 & Satisfied with current profitability of my company & 0.842 \\
\hline PERSAT2 & Satisfied with the current growth of my company & 0.871 \\
\hline PERSAT3 & Satisfied with the current non-financial performance of my company & 0.777 \\
\hline
\end{tabular}

The three-item scale to measure satisfaction with performance produced loadings ranging from 0.777 to 0.842 , with a coefficient alpha of 0.775 . Factor scores (regression method) were computed to serve as composite measures for each of the factors.

An analysis of variance (ANOVA) model was applied to test for differences in the five measures between the American and Mexican managers (see Table III). Significant differences at the 0.05 level were found in three of the five factors. Interestingly, no significant difference was found between the two groups in performance satisfaction. 
TABLE III

ANOVA: Factor scores for American vs. Mexican managers

\begin{tabular}{lcccc}
\hline Variable & American mean & Mexican mean & F-statistic & $P$-value \\
\hline & & & & \\
ART & 0.126 & -0.186 & 9.888 & 0.002 \\
HIDE & -0.101 & 0.127 & 5.125 & 0.024 \\
FLEX & 0.173 & -0.266 & 19.530 & 0.000 \\
RISK & 0.037 & -0.023 & 0.342 & 0.559 \\
TOP & -0.060 & 0.124 & 0.342 & 0.559 \\
PERSAT & -0.079 & 0.082 & 2.542 & 0.112 \\
\hline
\end{tabular}

\section{Findings and discussion}

The first proposition was supported. American managers were more likely to perceive strategy formulation as an art, whereas their Mexican counterparts viewed strategy formulation more as a science. As such, the data supports a number of previous findings.

The second proposition was not supported. American managers were more likely to believe that strategy content should be open, whereas their Mexican counterparts tended to emphasize the need to keep content hidden.

The third proposition was not supported. American managers were more likely to emphasize strategic flexibility, whereas their Mexican counterparts emphasized strategic consistency. Indeed, such commitment by Mexican firms to a set of core strategic principles can pay dividends to an organization by focusing its employees on a clear goal and increasing its predictability among customers and other key stakeholders. However, organizations must be capable of embracing positive change. The key for strategic managers is to identify the critical strategic parameters that should define the organization (e.g., quality, value, servicing a specific market niche, etc.), and promote flexibility within them.

The fourth proposition was supported. No significant difference was found between the American and Mexican managers along the dimension of risk. Strategic managers have a number of analytical and qualitative techniques at their disposal to transform their strategic environments in the direction of certainty. Strategic managers must identify key decision criteria and then develop systematic resources to glean current and reliable data that can readily drive these decisions. Acceptance of this view appeared to be equally accepted by American and Mexican managers.

The fifth proposition was not supported. No significant difference was found between the American and Mexican managers along the dimension of top management control of the process. This may be due to the fact that there is increasing evidence of increased participative management styles among managers in Mexican firms. Even the notion of self-managed work teams is gaining steam among Mexican organizations. For example, in one Sara Lee Knit Products plant, four managers are responsible for a work force of 900 production workers. Teams make decisions about production, technology, and even compensation (DeWitt, 1995; Stephens and Greer, 1995). Mexican workers have been found to value the interesting nature of work, quality production, and opportunities for learning (Noll, 1992). At least in the context of the present sample, the increase in participation may extend into strategic decision-making as well. 
Historically speaking, the trend toward bottom-up approaches to decision making is a recent phenomenon in the United States. Following this logic, executives should establish the strategy because they have the expertise and experience to "see the big picture." In many respects, this argument is still true. However, the increased education of the work force at all levels and the general trend toward decentralization over the past two decades suggest that a strict top-down approach may not yield the best strategy. American and Mexican managers appear to be equally split on this issue.

\section{Conclusions and directions for future research}

The academic answers to these key strategy dilemmas may be elusive, but two basic considerations govern the strategic manager's approach to them. First, the validity of the opposite extremes suggests that a working balance must be sought between the apparent contradictions. Second, each top executive must understand how the unique business environment in which he or she operates influences the proper response.

The findings in this study suggest that conventional wisdom on the nature of strategic management in Mexican firms (as compared to the U.S.) may not be true or may be changing. Specifically, the increased interest among Mexican managers in maintaining hidden strategies and strategic consistency is most noteworthy.

It is unlikely that research will substantially reduce the responsibility of top executives with respect to these five judgment calls. Nonetheless, a number of research implications emanate from an understanding of these critical issues. Scholars must recognize the assumptions on which their research programs are based and seek to address issues inherent in these assumptions. Failing to do so can severely limit or even eliminate the practical applications of their research, especially for managers who do not share their philosophical perspective.

Considering the art-science debate as an example, strategic managers who adopt the "strategy as art" perspective may not be willing to consider findings associated with the planning perspective. New or modified planning approaches will likely be seen as cumbersome, academic exercises devoid of practical relevance. In this case, researchers can strengthen the relevance and acceptance of their findings by addressing these concerns directly and, if possible, incorporating aspects of the alternative perspectives into their research designs and/or considerations of managerial implications.

A number of future research issues have been identified. First, the findings in the present study suggest that the Mexican philosophical approach to strategy is not well understood. Additional research on Mexican firms and industries could expand this knowledge, as well as assist both Mexican managers and those who work with them in understanding the perspectives they hold, and the advantages and disadvantages of each.

Second, managerial consensus-the degree to which managers agree on strategy-is a key consideration is the strategy measurement process (Bowman and Ambrosini, 1997; Thomas and Ramaswamy, 1996). This study did not address the extent to which managers in the same company might share a common philosophical approach.

Third, the measurement of performance has also plagued strategy researchers for more than two decades (Venkatraman and Ramanujam, 1986). While strategy researchers struggle with various performance measures such as return-on-assets, stock price and revenue growth, many companies are 
beginning to use a mixture of financial and non-financial measures for performance (Kaplan and Norton, 1997). Most researchers agree that multiple measures offer a rich perspective that cannot be seen by a single approach.

However, a consensus on which combination is most appropriate has not yet emerged (Wiliford, 1997). Although the present study considered only performance satisfaction, research in the field should follow a hybrid approach that is less susceptible to validity or reliability concerns associated with a single method.

Finally, the present study considered responses from managers from a variety of industries. As such, some factors associated with the perceptions of strategy and performance maybe industry-specific. Although the cross-industry approach has its advantages, additional studies that test for similar relationships within specific industries would be helpful.

\section{References}

Andrews, K.: 1971, The Concept of Corporate Strategy (Dow Jones, Homewood, IL).

Ansoff, H. I.: 1965, Corporate Strategy: An Analytical Approach to Business Policy for Growth and Expansion (McGraw-Hill, New York).

Bailey, T.: 1993, 'Organizational Innovation in the Apparel Industry', Industrial Relations 32, 30-48.

Barney, J. B.: 1991, 'Firm Resources and Sustained Competitive Advantage', Journal of Management 17, 99120.

Barney, J. B.: 1986, 'Strategic Factor Markets: Expectations, Luck, and Business Strategy', Management Science 32, 1231-1241.

Boeker, W.: 1989, 'Strategic Change: The Effects of Founding and History', Academy of Management Journal 32, 489-515.

Bowman, C. and V. Ambrosini: 1997, 'Perceptions of Strategic Priorities, Consensus and Firm Performance', Journal of Management Studies 34, 241-258.

Camerer, C. and A. Vepsalainen: 1988, 'The Economic Efficiency of Corporate Culture', Strategic Management Journal 9, 115-126.

Courtney, H., J. Kirkland and P. Viguerie: 1997, 'Strategy under Uncertainty’, Harvard Business Review (Nov.-Dec.), 67-79.

Cronbach, L. J.: 1951, 'Coefficient Alpha and the Internal Structure of Tests', Psychometrica 16, 297-334.

Dess, G. G. and P. S. Davis: 1984, 'Porter’s Generic Strategies as Determinants of Strategic Group Membership and Performance', Academy of Management Journal 26, 467-488.

DeWitt, J. W.: 1995, 'Even Better than in the U.S.', Apparel Industry Magazine 56(2), 36-38.

Dierickx, L. and K. Cool: 1989, 'Asset Stock Accumulation and Sustainability of Competitive Advantage', Management Science 35, 1504-1511.

Fiol, C. M.: 1991, 'Managing Culture as a Competitive Resource: An Identity-Based View of Sustainable Competitive Advantage', Journal of Management 17, 191-211.

Ford, C. M. and D. A. Gioia: 2000, 'Factors Influencing Creativity in the Domain of Managerial Decision Making', Journal of Management 26, 705-732.

Foxman, E. R., D. D. Muehling and P. W. Berger: 1990, ‘An Investigation of Factors Contributing to Consumer Brand Confusion’, Journal of Consumer Affairs 24, 170-189.

Gaertner, K. N.: 1989, 'Winning and Losing: Understanding Managers’ Reactions to Strategic Change', Human Relations 42, 527-545.

Gannon, M. J., K. G. Smith, and C. Grimm (1992, 'An Organizational Information-Processing Profile of First Movers', Journal of Business Research 25, 231-241.

Ghemawat, P. and T. Khanna: 2000, Tricon Restaurants International: Globalization Reexamined (Harvard Business School Press, Boston).

Greiner, L. E. and A. Bhambri: 1989, 'CEO Intervention and Dynamics of Deliberate Strategic Change’, 
Strategic Management Journal 10(Summer), 67-86.

Grewel, R. and P. Tansuhaj: 2001, 'Building Organizational Capabilities for Managing Economic Crisis: The Role of Market Orientation and Strategic Flexibility', Journal of Marketing 65(2), 47-80.

Guth, W. D. and I. C. Macmillan: 1986, 'Strategy Implementation Versus Middle Management Selfinterest', Strategic Management Journal 7, 313-327.

Gutierrez, S.: 1993, 'Can You Make it in Mexico?’, Financial Executive 9(2), 20-23.

Hambrick, D. C. and J. W. Fredrickson: 2001, 'Are You Sure You Have a Strategy?', Academy of Management Executive 15(4), 48-59.

Hamel, G. (1996, 'Strategy as Revolution’, Harvard Business Review (July-August), 69-82.

Hannan, M. and J. Freeman: 1977, 'The Population Ecology of Organizations', American Journal of Sociology 82, 929-964.

Harman, H. H. and W. H. Jones: 1966, 'Factor Analysis by Minimizing Residuals', Psychometrica 31, 351368.

Hart, S. L.: 1992, 'An Integrative Framework for Strategy-Making Processes', Academy of Management Review 17, 327-351.

Higgins, J. M.: 1983, Organizational Policy and Strategic Management, 2nd edn. (Dryden Press, Chicago).

Hitt, M. A., B. W. Keats and S. M. DeMarie: 1998, 'Navigating in the New Competitive Landscape: Building Strategic Flexibility and Competitive Advantage in the 21st Century', Academy of Management Executive 98 (12), 22-42.

Hoffman, B. (2001, 'What Makes a Strategy Brilliant?', Business Horizons ( July-August), 13-20

Husted, B. W., J. B. Dozier, J. T. McMahon and M. W. Kaftan: 1996, 'The Impact of Cross- National Carriers of Business Ethics on Attitudes about Questionable Practices and Form of Moral Reasoning', Journal of International Business Studies 27, 391-411.

Janis, I. L. (1972, Victims of Groupthink (Houghton- Mifflin, Boston).

Kaplan, R. S. and D. P. Norton: 1997, 'Why Does Business Need a Balanced Scorecard?’ Journal of Cost Management 11, 5-10.

Ketchen, D. J. and C. L. Shook: 1996, 'The Application of Cluster Analysis in Strategic Management Research: An Analysis and Critique’, Strategic Management Journal 17, 441-458.

Kotey, B. and G. G. Meredith: 1997, 'Relationships among Owner/Manager Personal Values, Business Strategies, and Enterprise Performance’, Journal of Small Business Management 35(2), 37-61.

Kras, E. S.: 1995, Management in Two Cultures (Intercultural Press, Yarmouth, ME).

Kuratko, D. F., R. V. Montagno and J. S. Hornsby: 1990, 'Developing an Intrapreneurial Assessment Instrument for an Effective Corporate Entrepreneurial Environment', Strategic Management Journal 11, 49-58.

Lado, A., N. Boyd and P. Wright: 1992, 'A Competency Based Model of Sustained Competitive Advantage: Toward a Conceptual Integration', Journal of Management 18, 77-91.

Lieberman, M. B. and D. B. Montgomery: 1988, 'First-Mover Advantages', Strategic Management Journal 9, (Summer), 41-58.

Loken, B., L. Ross and R. L. Hinkle: 1986, 'Consumer Confusion of Origin and Brand Similarity Perceptions', Journal of Public Policy and Marketing 5, 195-211.

Markoczy, L.: 2001, 'Consensus Formation During Strategic Change’, Strategic Management Journal 22, 1013-1031.

Mascarenhas, B.: 1992, 'First Mover Effects in Multiple Dynamic Markets', Strategic Management Journal 13, 237-243.

Michaelson, G. A.: 2001, Sun Tzu: The Art of War for Managers - Fifty Strategic Rules (Adams Media, New York).

Miles, R. E. and C. C. Snow: 1978, Organizational Strategy, Structure, and Process (West, New York).

Mintzberg, H.: 1987, 'Crafting Strategy', Harvard Business Review ( July-August), 66-75.

Mintzberg, H. and J. A. Waters: 1985, 'Of Strategies, Deliberate and Emergent', Strategic Management Journal 6, 257-272.

Morales, O.: 1997, ‘The Flip Side', Business Mexico 7(7), 32-33.

Nath, D. and D. Sudharshan: 1994, 'Measuring Strategy Coherence through Patterns of Strategic Choices', Strategic Management Journal 15, 43-61. 
Nayyar, P. R.: 1993, 'On the Measurement of Competitive Strategy: Evidence from a Large Multiproduct U.S. Firm', Academy of Management Journal 36, 1652-1669.

Nichol, R. L.: 1992, 'Get Middle Managers Involved in the Planning Process', Journal of Business Strategy 13(3), 26-32.

Nichols, C. E., H. W. Lane and M. B. Brechu: 1999, 'Taking Self-Managed Teams to Mexico', Academy of Management Executive 13(3), 15-25.

Noll, C. L.: 1992, 'Mexican Macquiladom Workers: An Attitude Toward Working', Southwest Journal of Business and Economics 9(1), 1-7.

Parnell, J. A.: 1997, 'New Evidence in the Generic Strategy and Business Performance Debate: A Research Note’, British Journal of Management 8, 175-181.

Petersen, B. and D. E. Welch: 2000, 'Creating Meaningful Switching Options in International Operations', Long Range Planning 33, 688-705.

Porter, M. E.: 1985, Competitive Advantage (Free Press, New York).

Saffold, G. S. III: 1988, 'Culture, Traits, Strength, and Organizational Performance: Moving Beyond "Strong Culture” ', Academy of Management Review 13, 546-558.

Sayles, L. R.:1993, 'Doing Things Right: A New Imperative for Middle Managers', Organizational Dynamics 21(4), 5-14.

Scarborough, J.: 1998, 'Comparing Chinese and Western Cultural Roots: Why "East is East and ...” ', Business Horizons 41(6), 15-24.

Schendel, D. E. and C. W. Hofer (eds.): 1979, Strategic Management (Little, Brown, Boston).

Smircich, L. and C. Stubbart: 1985, 'Strategic Management in an Enacted World', Academy of Management Review 10, 724-736.

Stephens, G. K. and C. R. Greer: 1995, 'Doing Business in Mexico: Understanding Cultural Differences’, Organizational Dynamics 24(1), 39-55.

Thomas, A. S. and K. Ramaswamy: 1996, 'Matching Managers to Strategy: Further Tests of the Miles and Snow Typology’, British Journal of Management 7, 247-261.

Ulrich, D.: 1987, ‘The Population Perspective: Review, Critique, and Relevance’, Human Relations 40, 137 152.

Venkatraman, N. and V. Ramanujam: 1986, 'Measurement of Business Performance in Strategy Research: A Comparison of Approaches', Academy of Management Review 11, 801-814.

Wall, J. A. Jr.: 1990, 'Managers in the People’s Republic of China', Academy of Management Executive 4(2), 19-32.

Walsh, J. P. and L. Fahey: 1986, 'The Role of Negotiated Belief Structures in Strategy Making', Journal of Management 12, 325-338.

Webb, J. and P. Dawson: 1991, 'Measure for Measure: Strategic Change in an Electronic Instruments Corporation', Journal of Management Studies 28, 191-206.

Wemerfelt, B. and A. Kamani: 1987, ‘Competitive Strategy under Uncertainty’, Strategic Management Journal 8, 187-194.

Westphal, J. D. and J. W. Fredrickson: 2001, 'Who Directs Strategic Change? Director Experience, the Selection of New CEOs, and Change', Strategic Management Journal 22, 1113-1137.

Whipp, R., R. Rosenfeld and A. Pettigrew: 1989, 'Managing Strategic Change in a Mature Business', Long Range Planning 22(6), 92-99.

Wiliford, S.: 1997, ‘ “Scorecard”: A New Way to Manage Business Strategy’, Memphis Business Journal 18(48), 7.

Wooldridge, B. and S. W. Floyd: 1990, 'The Strategy Process, Middle Management Involvement, and Organizational Performance’, Strategic Management Journal 11, 231-241.

Wright, P., M. Kroll, C. Pringle and J. Johnson: 1990, 'Organization Types, Conduct, Profitability and Risk in the Semiconductor Industry', Journal of Management Systems 2(2), 33-48.

Yoshihara, H.: 1990, 'Originality in Management', Journal for Quality and Participation (December), 14-21.

This article was originally published in the Journal of Business Ethics, 50(3), March 2004 